\title{
AIR PERMEABILITY OF POLYESTER NONWOVEN FABRICS
}

\author{
Guocheng Zhu, Dana Kremenakova, Yan Wang, Jiri Militky
}

Department of textile material engineering, Technical University of Liberec, Liberec, Czech Republic, Studentská 1402/2, Tel: +420 776109703, Email: zgc100100@hotmail.com

\begin{abstract}
:
Air permeability is one of the most important properties of non-woven fabrics in many applications. This paper aims to investigate the effects of thickness, porosity and density on the air permeability of needle-punched non-woven fabrics and compare the experimental values with two models which are based on hydraulic radius theory and drag theory, respectively. The air permeability of the samples was measured by an air permeability tester FX3300. The results showed that the air permeability of non-woven fabrics decreased with the increase in thickness and density of samples, increased with the increase of porosity, and the air permeability was not directly proportional to the pressure gradient. Meanwhile, the prediction model based on hydraulic radius theory had a better agreement with experimental values than the model based on drag theory, but the values were much higher than the experimental results, especially for higher porosity and higher pressure gradient.
\end{abstract}

\section{Keywords:}

air permeability; non-woven fabric; porosity; thickness

\section{Introduction}

Air permeability describes the rate of flow of a fluid through a porous material, and the mathematical expression is given by

$$
q=Q / A t
$$

Where $q$ is rate of flow $(\mathrm{m} / \mathrm{s}), Q$ is volume of flow of fluid through the sample $\left(\mathrm{m}^{3}\right), t$ is time (s) and $A$ is the cross-sectional area $\left(\mathrm{m}^{2}\right)$.

Non-woven fabrics stand out as a unique class of porous media, which contain relatively high volume of air and very complex structure due to the random arrangement of fibres. Air permeability is one of the most important properties of nonwoven fabric in many applications,

Numerous researchers have worked on the air permeability of non-woven fabrics in both experiment [1-3] and analytical prediction [4-7]. In general, two theories are applied for predicting the air permeability of porous materials: the first based on hydraulic radius theory, and the second based on drag theory.

Darcy derived an equation for calculating the air permeability based on hydraulic radius theory, which states that rate of flow is directly proportional to the pressure gradient causing the flow[8]. The equation is as follows:

$$
q=\frac{k_{p} \cdot \Delta p}{\mu \cdot L}
$$

Or

$$
Q=A \cdot t \cdot \frac{k_{p} \cdot \Delta p}{\mu \cdot L}
$$

Where $q$ is the rate of flow $(\mathrm{m} / \mathrm{s}), k p$ is the flow permeability coefficient $\left(\mathrm{m}^{2}\right), \Delta p$ is the pressure gradient (pa), $\mu$ is the viscosity of the flow (pa.s), $L$ is the thickness of sample $(\mathrm{m}), Q$ is the volume flowing in time $\left(\mathrm{m}^{3}\right), A$ is the cross-section area $\left(\mathrm{m}^{2}\right)$ where flow goes through, $t$ is time (s).

The key parameter for predicting air permeability is the permeability coefficient. Kozeny and Carman[8] proposed another equation to determine the permeability coefficient for homogeneous porous materials having porosity less than 0.94 , and then Davies [9] extend this work and empirically derived a mathematical expression for predicting the air permeability coefficient of non-woven fabrics having porosity in the range of 0.7-0.994. Mohammadi[5] modified the Kozeny formula by introducing Davies' permeability coefficient to predict air permeability of layered non-woven fabrics. The mathematical expression of permeability coefficient is given by

$$
k_{p}=\frac{d^{2} \varepsilon^{3}}{16 k_{D} \mu(1-\varepsilon)^{2}}
$$

Where $d$ is fibre diameter $(\mathrm{m}), \varepsilon$ is porosity, $\mu$ is the viscosity of the flow (pa.s), $k D$ is the Davies constant, which is given by

$$
k_{D}=\frac{4 \varepsilon^{3}(1-\varepsilon)^{1.5}\left[1+56(1-\varepsilon)^{3}\right]}{(1-\varepsilon)^{2}}
$$

From a different point of view, the drag theory leads to a different expression for the dependence of resistivity on porosity than that given by the hydraulic radius theory. Some researchers[7] reported that the drag theory can explain the air permeability of porous materials. The air permeability of porous materials is given by [7]

$$
q=\frac{1}{9.4} \cdot \frac{\Delta p}{L \cdot \mu} \cdot \frac{\left(\rho_{f}-\rho_{n}\right) \cdot d^{2}}{\rho_{n}} \cdot \frac{2-\ln R_{e}}{2.4-\ln R_{e}}
$$


Where $q$ is the rate of flow $(\mathrm{m} / \mathrm{s}), \Delta \mathrm{p}$ is the pressure gradient (pa), $\rho f$ and $\rho n$ are the fibre and non-woven fabric densities $(\mathrm{kg} /$ $\left.\mathrm{m}^{3}\right), d$ is the fibre diameter $(\mathrm{m}), L$ is the thickness of sample, $\mu$ is the viscosity of the flow (pa.s), Re is Reynolds number, which is given by

$$
R_{e}=\rho v d / \mu
$$

Where $\rho$ is fluid density $\left(\mathrm{kg} / \mathrm{m}^{3}\right)$ and $v$ is fluid velocity $(\mathrm{m} / \mathrm{s})$.

In this work, some non-woven fabrics with various parameters such as density, porosity and thickness were prepared in a carding machine and a needle-punched machine. The air permeability of non-woven fabrics was measured in an air permeability tester FX3300. The experimental results were compared with analytical models based on these two theories, and the effects of some parameters on the air permeability were discussed.

\section{Experiment}

Polyester hollow fibres (supplied by Sinopec Yizheng Chemical Fibre Company Limited) were used to prepare non-woven fabrics in carding machine and needle-punching machine at our laboratory. After keeping non-woven fabrics at a constant temperature and constant humidity box for 24 hours, the nonwoven fabrics were measured.

The profiles of hollow fibres and non-woven fabrics were observed by scanning electron microscopy (SEM). The thickness was measured by an Alambeta instrument, which enables quick measurement of the sample thickness under a $200 \mathrm{~Pa}$ contact pressure[10]. The air permeability was measured by air an permeability tester FX3300, which

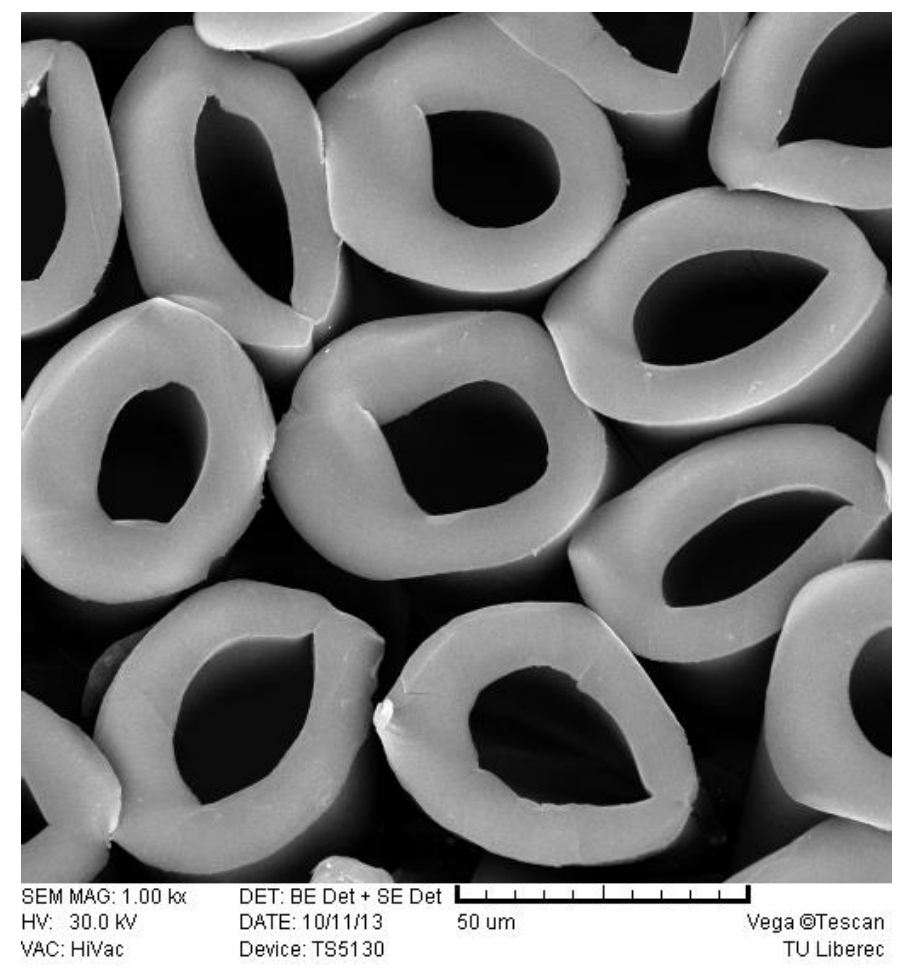

measures airflow rate under constant air pressure drop. Five samples from each non-woven fabric were measured and an average value was determined.

\section{Results and discussions}

\section{Determination of the structural characteristics of non- woven fabric}

In non-woven fabrics, pores of all geometrical shapes are possible because of the random arrangement of fibres. Some researchers stated that the air permeability of non-woven fabrics is related to the fibre diameter, porosity, pore size and pore shape or tortuosity factor [11, 12].

According to the images of the fibres (figure 1), the mean fibre diameter was around $45 \pm 5 \mu \mathrm{m}$, hollow diameter was $22 \pm$ $3 \mu \mathrm{m}$, and the air volume content was $27 \pm 8 \%$. Hollow fibre density was $1034 \mathrm{~kg} / \mathrm{m}^{3}$, which was calculated by

$$
\rho_{f}=\frac{n \cdot m}{\pi\left(r_{1}^{2}-r_{2}^{2}\right) l \cdot n}
$$

Where $\rho f$ is fibre density $\left(\mathrm{kg} / \mathrm{m}^{3}\right), n$ represents the number of fibres, $m$ represents mass of single fibre $(\mathrm{kg}), r 1$ and $r 2$ represent fibre diameter and hollow diameter $(\mathrm{m}), \mathrm{I}$ represents length of single fibre $(\mathrm{m})$.

The porosity of non-woven fabric is given by

$$
\varepsilon=\left(1-\frac{\rho_{n}}{\rho_{f}}\right) \times 100 \%
$$

Where $\varepsilon$ is the porosity of non-woven fabric, $\rho n$ and $\rho f$ are the densities of non-woven fabric and fibre $\left(\mathrm{kg} / \mathrm{m}^{3}\right)$, respectively.

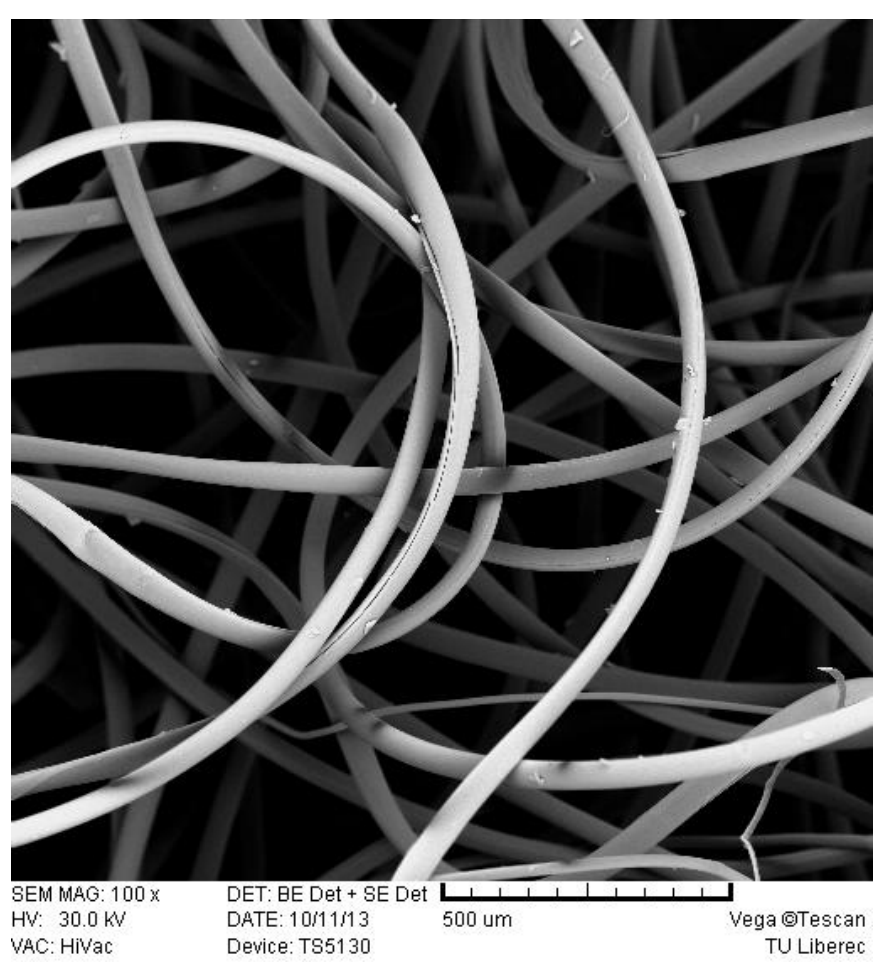

Figure 1. Images of hollow fiber and nonwoven fabric 
The mean effective pore diameter of non-woven fabrics is given by Verschoor[13]:

$$
D=\frac{\pi d}{4(1-\varepsilon)}
$$

Where $D$ is the mean effective pore diameter $(\mathrm{m}), d$ is the mean fibre diameter $(\mathrm{m})$ and $\varepsilon$ is the mean porosity of the sample.

\section{The relation of density and porosity}

Obviously, the density of non-woven fabric is inversely proportional to the porosity of non-woven fabric according to equation (9), and figure 2 also shows the relationship between the density and porosity of non-woven fabrics. The density had a wider change with respect to the change of porosity.

\section{The effect of thickness on air permeability}

According to equations (2) and (6), the air permeability would decrease with increase in thickness of non-woven fabrics, and the experimental results showed the same trends (figure 3 ). However, the predicted values were much higher than the

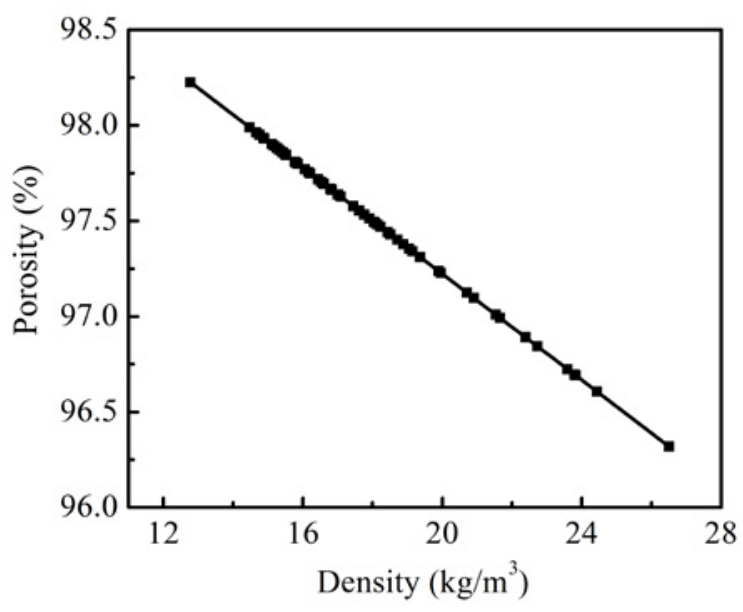

Figure 2. The relation of density and porosity

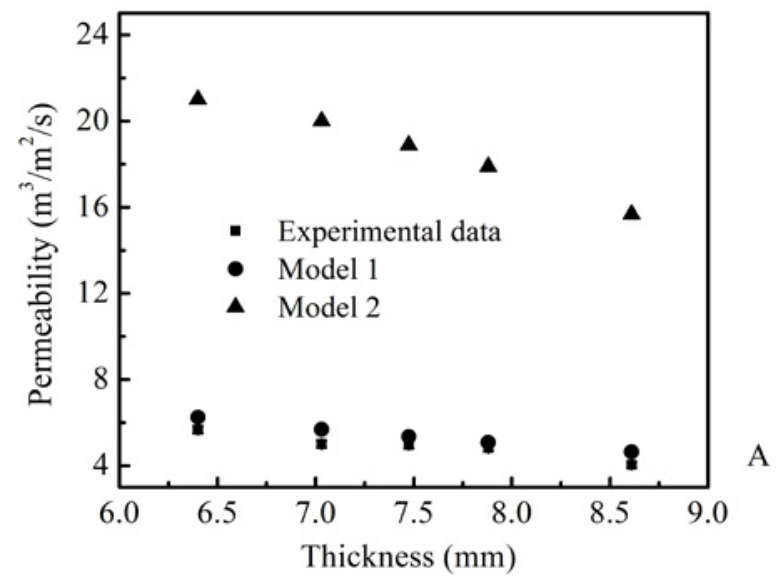

experimental values, especially for model 2 , which is based on drag theory. Meanwhile, the prediction of models becomes worse with the increase in pressure gradient.

Higher predicted values from model 1 might be due to the assumption that the non-woven fabrics are ordered structures, which is different from reality. The mean hydraulic radius cannot be easily defined. Higher predicted values from model 2 might be due to the much higher Reynolds number, which is the key factor associated with an intrinsic variation of drag. For model 2, the Reynolds number is limited around 1[7]. Therefore, analytical determination of air permeability of nonwoven fabrics is still very challenging.

\section{The effect of porosity on air permeability}

Air permeability of non-woven fabrics increases with the increase in porosity, and the predicted values from model 1 are higher than the experimental results, especially when the porosity and the pressure gradient are increasing (figure 4). The predicted values based on model 2 were not given due to the limitation of Reynolds number. Model 1 stated the correlation between permeability and porosity. However, some researchers[14, 15] concluded that there is no simple correlation between permeability and porosity because of the strong dependence of flow rate on the width, shape and tortuosity of the conducting channels. Piekaar[11] and Clarenburg[12] point out that the tortuosity factor, the ratio of the effective or tortuous channel length and the sample thickness are important parameters in determining flow through non-woven fabrics.

\section{The effect of density on air permeability}

According to figures 2 and 4 , it is obvious that the air permeability of non-woven fabrics would decrease with the increase in density, and the experimental results gave the same trends (figure 5). Therefore, density might not be an important parameter as it can be replaced by porosity. Besides, density cannot provide any detail information about the pore size and pore shape.

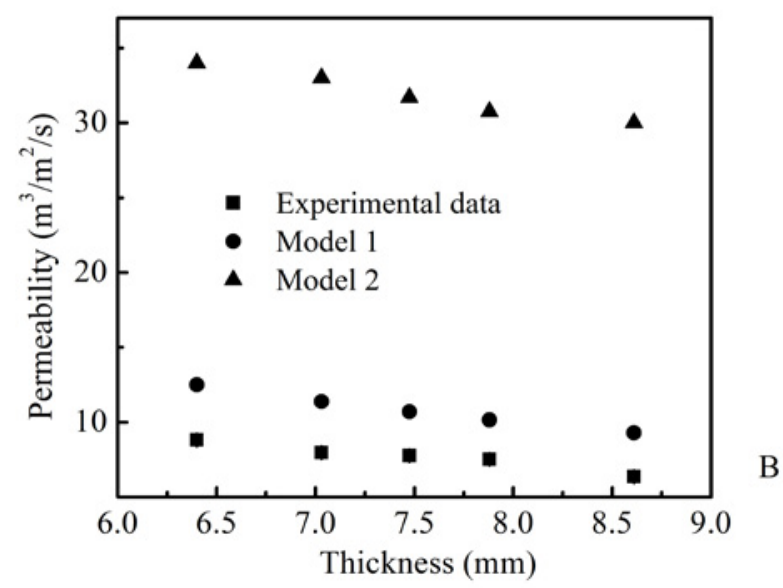

Figure 3. Effect of thickness on air permeability of nonwoven fabrics with density $15.34 \pm 0.16 \mathrm{~kg} / \mathrm{m} 3$. (A) $100 \mathrm{~Pa}$ pressure gradient ; (B) $200 \mathrm{~Pa}$ pressure gradient. 

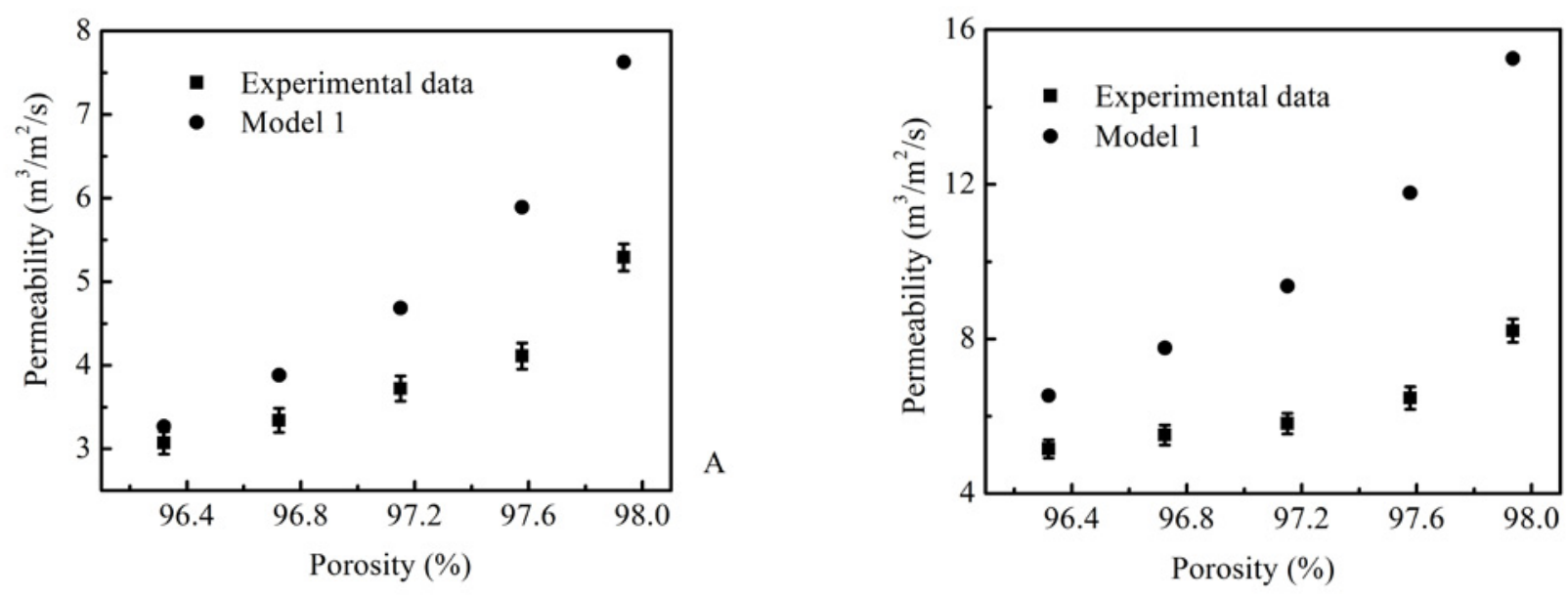

Figure 4. Effect of porosity on permeability of nonwoven fabrics with $7.58 \pm 0.05 \mathrm{~mm}$ thickness (A) 100pa pressure gradient; (B) 200pa pressure gradient.
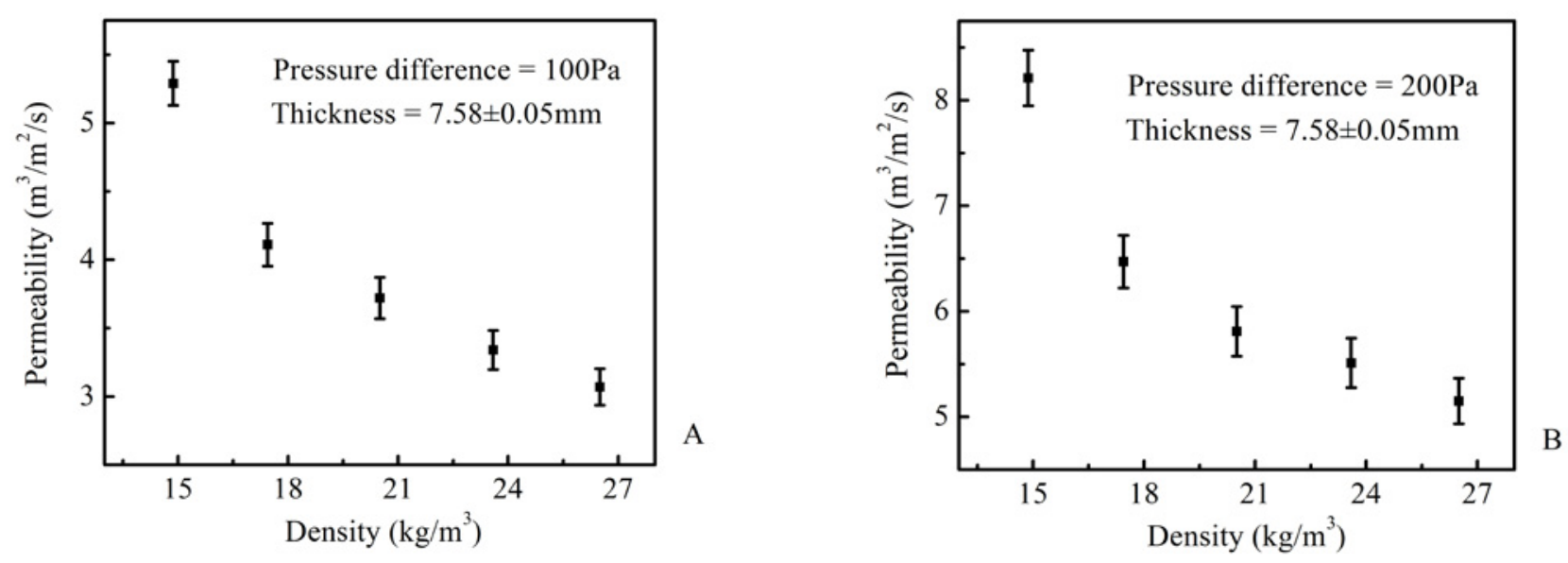

Figure 5. Effect of density on permeability of nonwoven fabrics with $7.58 \pm 0.05 \mathrm{~mm}$ thickness (A) 100pa pressure gradient; (B) 200pa pressure gradient.

\section{The effect of pressure gradient on air permeability}

Model 1 implied that the air permeability would be directly proportional to the pressure gradient, but the experimental results demonstrated that the air permeability of samples under a $200 \mathrm{~Pa}$ pressure gradient was 1.6 times higher than the air permeability of samples under a $100 \mathrm{~Pa}$ pressure gradient.

\section{Conclusion}

Air permeability of non-woven fabrics with different structures was investigated in this study. Some conclusions can be made based on the results: (1) the air permeability of nonwoven fabrics decreased with the sample's thickness and density, increased with the increase of porosity and the air permeability was not directly proportional to the pressure gradient; (2) the prediction model based on hydraulic radius theory had a better agreement to experimental values than the model based on drag theory; but the values were much higher than the experimental results, especially for higher porosity and higher pressure gradient. Therefore, more work is needed for improving the accuracy of prediction model

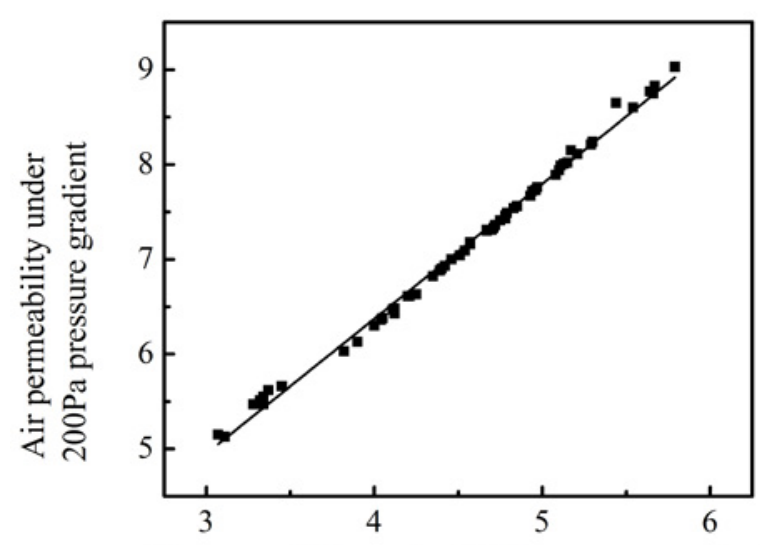

Air permeability under $100 \mathrm{~Pa}$ pressure gradient

Figure 6. The effect of pressure gradient on air permeability

which may be needed to take pore size and pore shape into consideration. 


\section{Acknowledgement}

This work is supported under Student Grant Scheme (SGS 48013/115) by Technical University of Liberec, Czech Republic.

\section{References}

[1] Kothari, V.K. and A. Newton, Air-Permeability of NonWoven Fabrics. Journal of the Textile Institute, 1974. 65(10): p. 525-531.

[2] Mohammadi, M. and P. Banks-Lee, Air permeability of multilayered nonwoven fabrics: Comparison of experimental and theoretical results. Textile Research Journal, 2002. 72(7): p. 613-617.

[3] Debnath, S. and M. Madhusoothanan, Thermal resistance and air permeability of jute-polypropylene blended needlepunched nonwoven. Indian Journal of Fibre \& Textile Research, 2011. 36(2): p. 122-131.

[4] Kulichenko, A.V., Theoretical analysis, calculation, and prediction of the air permeability of textiles. Fibre Chemistry, 2005. 37(5): p. 371-380.

[5] Mohammadi, M. and P.B. Lee, Air permeability of multilayer needle punched nonwoven fabrics: Theoretical method. Journal of Industrial Textiles, 2002. 32(1): p. 45-57.

[6] Song, W.F. and W.D. Yu, Fractal calculation of air permeability of nonwoven fabrics. Journal of the Textile Institute, 2012. 103(8): p. 817-826.
[7] Iberall, A.S., Permeability of Glass Wool and Other Highly Porous Media. Journal of Research of the National Bureau of Standards, 1950. 45(5): p. 398-406.

[8] Carman, P.G., ed. Flow of Gases through Porous Media. 1956, Butterworth Scientific Pubications: London.

[9] Davies, N.C. The separation of airborne dust and particles. 1952. London: Proceedings of institute of mechanical engineers.

[10] Lubos Hes and I. Dolezal, New method and equipment for measuring thermal properties of textiles. Journal of the textile machinery society of Japan, 1989. 42: p. 71-75.

[11] Piekaar, H.W. and Clarenbu.La, Aerosol Filters - Tortuosity Factor in Fibrous Filters. Chemical Engineering Science, 1967. 22(12): p. 1817-1827.

[12] Clarenbu.La and H.W. Piekaar, Aerosol Filters .I. Theory of Pressure Drop across Single Component Glass Fibre Filters. Chemical Engineering Science, 1968. 23(7): $p$. 765-771.

[13] Verschoor, D.J. and Greebler, Heat Transfer by Gas Conduction and Radiation in Fibrous Insulation. Trans. ASME, 1952. 74: p. 961.

[14] Scheidegger, A.E., ed. The Physics of Flow through Porous Media. 1957, University of Toronto Press: Toronto, Canada.

[15] Hillel, A., ed. Fundamentals of Soil Physics. 1980, Academic Press: New York. 